International Journal of Database Management Systems ( IJDMS ) Vol.4, No.2, April 2012

\title{
E-ProcurEMENT SySTEM WiTH EMBEDDED SUPPLIER SELECTION DSS FOR AN AUTOMOBILE MANUFACTURING INDUSTRY
}

\author{
P.Priya ${ }^{1}$, Dr.K.Iyakutti ${ }^{2}$, Dr.S.Prasanna Devi ${ }^{3}$ \\ Research Scholar, Bharathiar University, Coimbatore, India ${ }^{1}$ \\ priyax80@rediffmail.com \\ Professor, Madurai Kamarajar University, India ${ }^{2}$ \\ iyyakutti@gmail.com \\ Associate Professor, Apollo Engineering College, Chennai, India ${ }^{3}$ \\ prasannasivallegmail.com
}

\begin{abstract}
This paper presents the development of Decision Support System (DSS) to enable the selection of best suppliers in an e-procurement process. The model base of the DSS incorporates the Online Analytical Processing (OLAP) and Analytic Hierarchy Process (AHP) techniques to shortlist and selects the best suppliers in a web environment. The e-DSS process is implemented using ASP and SQL server, for an Indian automobile manufacturing industry. The results obtained for supplier selection is competitive in terms of the quality and lead time of the chosen suppliers.
\end{abstract}

\section{KEYWORDS}

AHP, Decision Support System, E-commerce, E-procurement, Supplier selection, OLAP

\section{INTRODUCTION}

The Internet allows the supplying of enterprises from the smallest enterprise to largest corporations to establish global presence. Hence, the supplying enterprises now have the opportunity to reach geographically dispersed markets that would otherwise be cost prohibitive to consider. Purchasing enterprises also now have the opportunity to select the best suppliers, by utilizing suppliers' bids on the internet, thus averting time consuming and costly outside sources (middlemen). By best supplier, it means the supplier who can supply the right amount of material at the right time at right price (or cheap), and of the right quality. Hence the choice of suppliers plays an important role in reducing the wastage in the supply chain and hence shows an initiative towards business process improvement.

The increasingly competitive global world markets put industries under intense pressure to find ways to cut material costs to survive and sustain their competitive position in their respective markets. Since a qualified supplier is a key element and a good resource for a buyer in reducing 
International Journal of Database Management Systems ( IJDMS ) Vol.4, No.2, April 2012

such costs, evaluation and selection of the potential suppliers has become an important component of supply chain management. Hence, development of an effective and rational supplier selection model is naturally desirable. A review of literature has been made to study the different techniques used for the supplier selection in an procurement/ e-procurement process.

Saman Hassanzadeh Amin et al (2011) have proposed a new framework for supplier management of Internet Service Provider (ISP) on the basis of company's strategy including supplier selection, evaluation, and development. In the first phase, quality function deployment is utilized to rank the best ISPs based on qualitative criteria. Then a Quantitative model is adopted to consider quantitative metrics.

Cemalettin Kubat et al (2010) have integrated AHP, Fuzzy AHP and Genetic Algorithm to determine the best suppliers. Fuzzy set has been utilized to linguistic factor to organize criteria and sub criteria weight, pair wise comparison with fuzzy AHP where it is utilized to organize all factors and which was assigned weighting for related factors. Finally, a hypothetical supplier selection problem was solved by GA algorithm

Ali kokangul et al (2009) have developed an integrated approach of AHP and non-linear integer and multiobjective programming to determine the best suppliers and to place the optimal order quantities among them. This integration based multi-criteria decision making methodology takes into account both qualitative and quantitative factors in supplier selection. While AHP matches item characteristics with supplier characteristics, non-linear integer programming model analytically determines the best suppliers and the optimal order quantities among the determined suppliers.

Jose M.Cruz (2009) have developed a decision support frame work for modelling and analysis of supply chain networks incorporating social responsibility (CSR) and have considered the multicriteria decision making behaviour of the various decision makers (manufacturers, retailers, and consumers), which includes the maximization of net return, the minimization of emission, and the minimization of risk.

Ming -Hung Shu et al (2009) have proposed a supplier selection and evaluation problem on the basis of the quality criteria. Here the cpk indexes have been used to evaluate the quality of supplier's product.

Suleyman Ersoz et al (2009) have developed an expert system to give rational decisions in vendor selection in which management and selection of vendors have been examined by considering the various factors like quality, service, speed, cost etc.

Jing-Rung Yu et al (2008) proposed a framework which integrates the Analytic Hierarchy Process and integer programming to rate suppliers' performance regarding incoming raw materials in the context of supplier management and then to allocate periodical purchases.

Wan Lung Ng (2008) proposed a weighted linear program for the multi- criteria supplier selection problem.

Zhiying Liao et al (2007) presented a model on multi-objective stochastic supplier selection model which is a typical non-linear mixed integer combinatorial optimization problem developed 
International Journal of Database Management Systems ( IJDMS ) Vol.4, No.2, April 2012

to minimize the cost, average quality rejection rate, delivery rate and maximize the flexibility rate.

Manoj kumar et al (2006) have developed and formulated a fuzzy multiobjective integer programming Vendor selection problem that incorporates the three important goals: cost minimization, quality maximization and maximization of on time delivery with the realistic constraints such as meeting the buyer's demand, vendor's capacity, and vendor's quota flexibility.

Ozden Bayazit et al (2005) for the first time discussed a comprehensive application of AHP for a real-world case along with sensitivity analysis to choose the best supplier. They proposed an AHP model to choose the best supplier and place the order quantities among them for a construction company.

Qualitative and quantitative factors used to identify a potential good supplier has been taken from the above stated literature papers. However the literature does not report the implementation of the supplier selection process integrated in an e-procurement process. Also, the use of OLAP technique for multi-criteria decision making for deciding the supplier selection strategies in the early phase of e-procurement is not reported in the literature. Hence, this paper explores the development of Decision Support System (DSS) for the supplier selection process in an Eprocurement process, i.e., automatically searching suppliers on the servers, and filtering the data to find the best supplier. By this DSS, an enterprise can seek potential suppliers from all over the world, faster and cheaper. Also, an enterprise can seek suppliers often, for an ongoing project or for future projects. Hence a DSS framework has been developed for supplier selection procedures that enable the enterprise to maintain its key concepts for survival, namely agility and dynamic collaboration.

Section 2 presents the design details for implementation of the DSS, which enables potential short listing of the good suppliers. Section 3 illustrates the implementation of the e-procurement process with the selected list of suppliers, for the final selection of the best supplier for contract. Section 4 presents the conclusions of the paper.

\section{DESIGN AND IMPLEMENTATION OF E-DSS}

The electronic Decision Support System (e-DSS) framework shown in Figure 1 first determines the characteristics and requirements of the procurement cycle. The strategic decision making involves the demand analysis, fixing up the procurement horizon and determine the sourcing strategy. Once this is finalized, the buying organization invites all suppliers to participate in the supplier selection bid. Any supplier around the globe can participate in the selection process by registering with the buying organization by providing all the relevant data required. These data's are stored in the supplier's database. The profile submitted by every supplier can be modified/ updated at any point of time in order to show their continuous improvement in terms of quality rating, cost rating, cycle time rating, organization rating, relationship rating, service rating and past performance rating.

The supplier selection process is initiated with the screening of potential suppliers based on the procurement requirement. The screening is based on strategic decisions made such as (i) choosing the supplier of specific geographic location (like local suppliers, regional / national / international suppliers), (ii) choosing based on the manufacturing strategy (MTO/MTS/MFS), (iii) choosing 
International Journal of Database Management Systems ( IJDMS ) Vol.4, No.2, April 2012

the supplier based on their relative performance rating and so on. Once the supplier selection list is finalized, the e-procurement process can then follow.

The user interacts with the interface which is basically a graphical user interface (GUI). Using the GUI the user can key in data and also retrieve data using the 'Data Acquisition System (DAS). It is this DAS that interacts with all the modules of the DSS.

The DAS first interacts with the knowledge database. This is the permanent database that stores all details regarding the suppliers, process details and also the performance data.

The DAS also interacts with the dynamic database. This dynamic database can also be called the temporary database. It is this database from which we can export the data to the SPSS software for OLAP analysis.

The link engine is the engine that establishes the link between the dynamic database and the SPSS database. Once the data is exported to the SPSS database the OLAP analysis can be executed from a command executed by the user.

There is also a dynamic data acquisition module. With the help of this module the user can edit any existing data and append new data to the existing database. This can be useful in the case there is any change in the supplier's performance or parameters. This is usually done by a human expert, who is normally a supplier assessor in the buying organization or by the supplier himself by means of self-evaluation. Apart from all these, the user can store data and retrieve them at any future point.

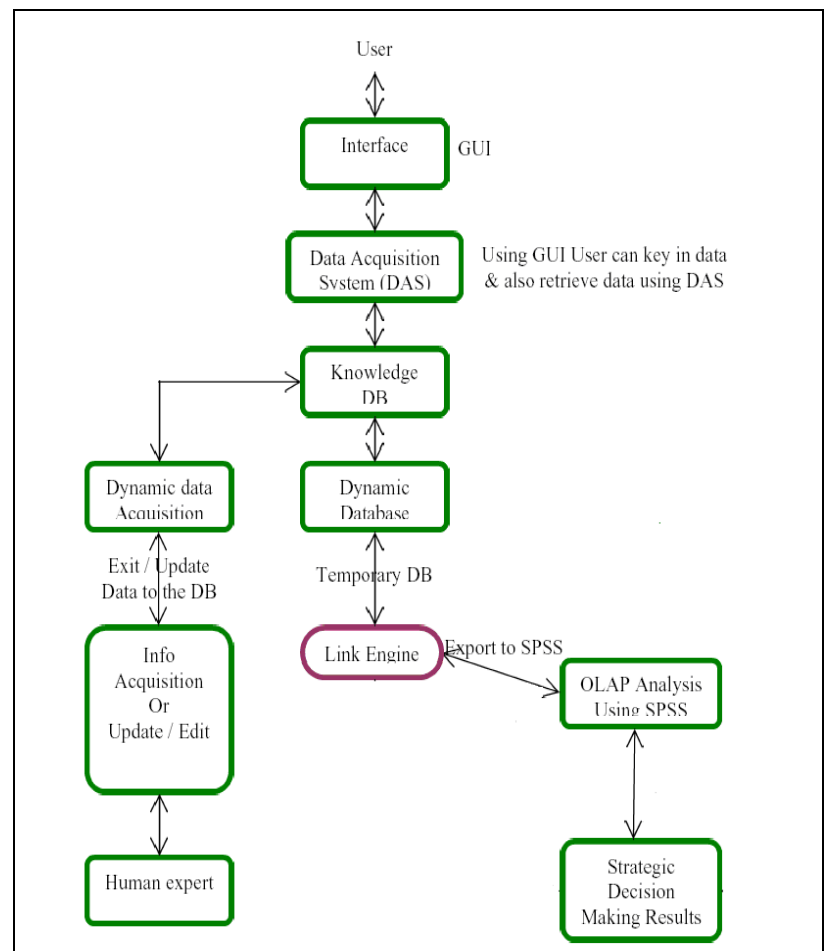

Figure 1 Framework of Supplier Selection DSS 
International Journal of Database Management Systems ( IJDMS ) Vol.4, No.2, April 2012

The implementation of DSS is done with ASP.Net as the front end for user interface. Any supplier willing to partner with the buying organization needs to submit their profile which can be updated at any time. This enables continuous monitoring of the supplier improvement towards business process improvement. The buying organization will make use of this supplier database information to make strategic decisions in selecting the best supplier among the very large list of potential suppliers. The Model View Controller (MVC) pattern of DSS implementation is shown in Figure 2.

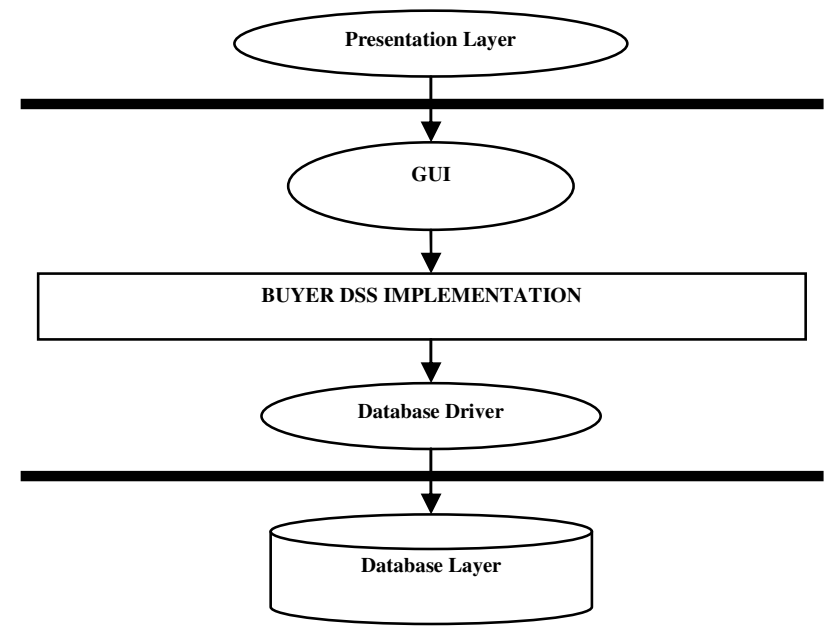

Figure 2 MVC Pattern of DSS Implementation

The structure of the buyer DSS implementation comprises of the following sub-modules. They are described as follows:

\section{(A) Supplier Profile Submission or Update Component}

The supplier profile submission or update component is used by the buying organization to get as much information about the supplier. This supplier profile will be stored in their supplier's database from which they can screen the potential suppliers whoever matches their screening criteria. The information provided can be updated by the supplier at any time.

\section{(B) Supplier Self - Evaluation Component}

Supplier selection criteria are an important issue in the supplier selection process. A self evaluation form is framed based on the study of factors affecting supplier selection and given to the suppliers to provide input to the buying organization in-order to help the buying organization to better understand their business practices and standards. Formulation of the self - evaluation criteria's \& the factors influencing each decision criteria towards understanding of the supplier, as collected from the automobile industry is given in Appendix 1. This form has to be submitted by the supplier during their participation in the supplier's selection bid. The supplier has to evaluate/rate himself based on many criteria's such as the cost, quality, cycle time, organization standards, past performance, relationship with other organizations and service level. Based on the evaluation their performance is recorded and will be monitored by the Supplier assessment team of the buying organization. This evaluation data provided by the supplier will be used by the buying organization to make strategic decisions. The validity of the information provided will be 
International Journal of Database Management Systems ( IJDMS ) Vol.4, No.2, April 2012

assessed by a team from the buying organization, after which the supplier will be considered for the selection process. The supplier can update their rating as and when they update their business standards/ practices. This helps the buying organization to keep track of the supplier performance improvement or monitor the continuous improvement of the supplier which aids towards TQM.

The supplier is rated based on the information provided by them. The overall supplier performance is calculated based on the average of the ratings obtained in terms of: Quality, Cost, Relationship, Organization, Service, Cycle time and Past performance rating.

The supplier can update the self-evaluation procedure as and when they show an initiative towards business improvement. The performance rating thus calculated by this process is used to continuously monitor the improvement of the supplier towards its business improvement initiatives.

The supplier self-evaluation form shown in Fig 3 is used to evaluate the supplier performance based on the data submitted by them. The authenticity and validity of the information provided by the supplier will be verified by the supplier assessment team (SAT). The supplier is evaluated in terms of Cost, Quality, Service, Past Performance, Relationship, Organization and Cycle time are evaluated. The supplier rating is evaluated as per the information provided by the supplier.

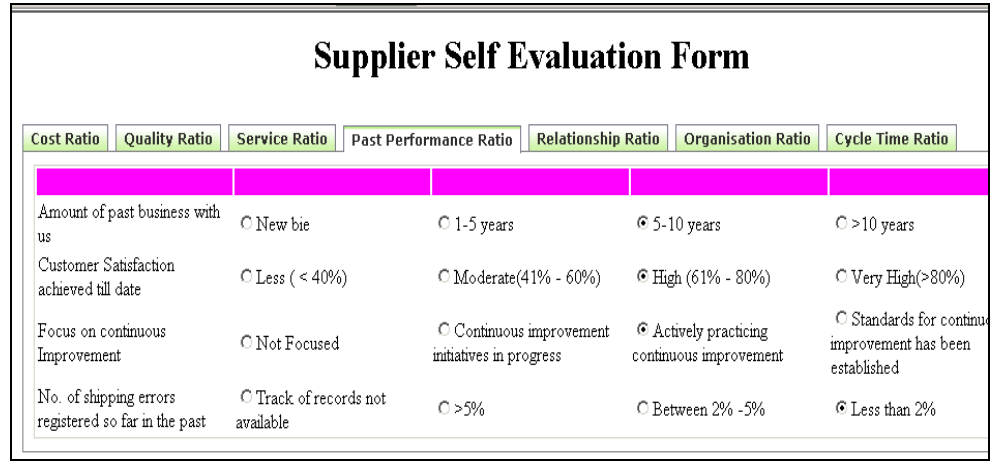

Figure 3. Supplier self evaluation component.

\section{(C) OLAP Using SPSS}

Multidimensional OLAP using SPSS is used for making strategic decisions. The possible dimensions of supplier selection decisions are the Location (Local, Regional, National, International), Manufacturing strategy (MTS, MTO, MFS, etc.), Type of product. In all cases, the performance rating is taken into account as the quantitative measure used for the decision making process. The ODBC connectivity is interfaced with the SPSS software for the OLAP analysis.

OLAP databases are referred often as "cubes" since they have a multidimensional nature. Each result of querying, browsing, and summarizing can be viewed and stored as a separate cube. A cube is a visual representation of a multidimensional table and has just three dimensions: rows, columns and layers. OLAP cubes are very flexible because they allow the user to move information between these three dimensions. OLAP cubes are easy to create and manipulate. Since they provide insight into various aspects of data, these tools also represent data mining technology. Figure 4 shows the OLAP cube for the decision making process with three dimensions: The supplier, location and product. 


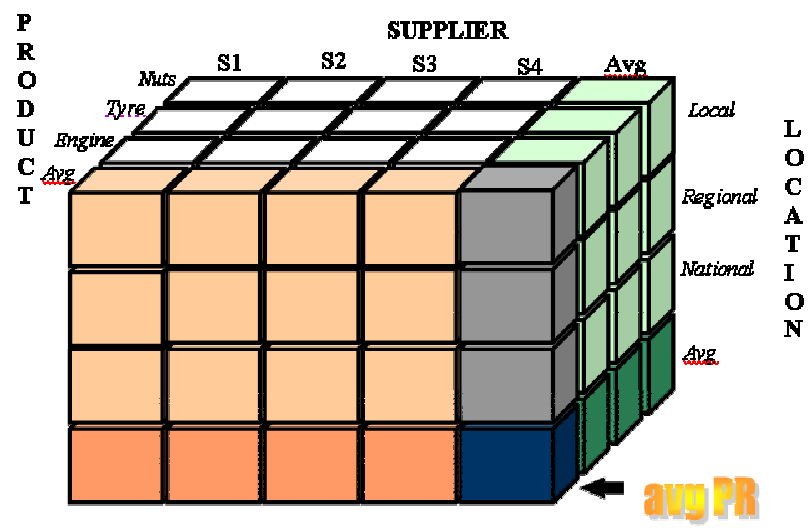

Figure 4 Data cube construction for Supplier selection process

With this cube creation, an OLAP analysis can be performed to make decisions. If the OLAP cube gives a higher performance rating for local suppliers (High mean value of performance rating for suppliers whose location type="local") as compared to others (Regional, national, international) then, the decision of supplier selection favours the choice of selecting local suppliers. Similarly, OLAP can be used to find out which product performance is good, so as to bring in focus to other products whose performance is not up to the expected level.

From the Performance Level of all the " $n$ " suppliers, Multidimensional OLAP is performed using SPSS for making strategic decisions. The OLAP operations such as Slice and Dice shown in Figure. 5 are done on the OLAP cube. The slice operation performs a selection on one dimension of the given cube resulting in a sub cube. The dice operation defines a sub cube by performing a selection on two or more dimensions. OLAP is an approach to quickly provide the answer to analytical queries that are dimensional in nature. OLAP is technology that uses a multidimensional view of aggregate data to provide quick access to strategic information for further analysis. It allows fast and efficient analysis of data by turning raw data into information that can be understood by users and manipulated in various ways. So OLAP technique is used for multidimensional analysis of supplier's performance and determines the criteria for procurement process.

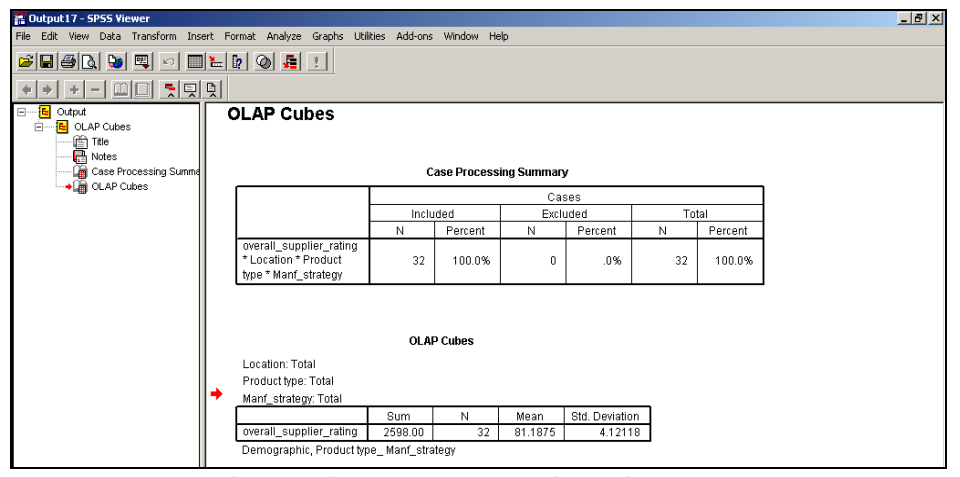

Figure 5 OLAP operations in SPSS 
International Journal of Database Management Systems ( IJDMS ) Vol.4, No.2, April 2012

\section{(D) Screening \& Short-Listing of Suppliers}

The filtering process is based on the selection strategies decided by the Decision authorities, such as based on the attributes such as: Manufacturing strategy and location as shown in Figure 6. The results of the screening module are used to rank the suppliers as shown in Figure 7. The Operations Research based Analytic Hierarchic Process (Saaty, 2000) is used for ranking among supplier alternatives. The results of selecting the best " $n=4$ " suppliers for the chosen criteria quality, cost, service, delivery and environment are shown in Figure. 8.

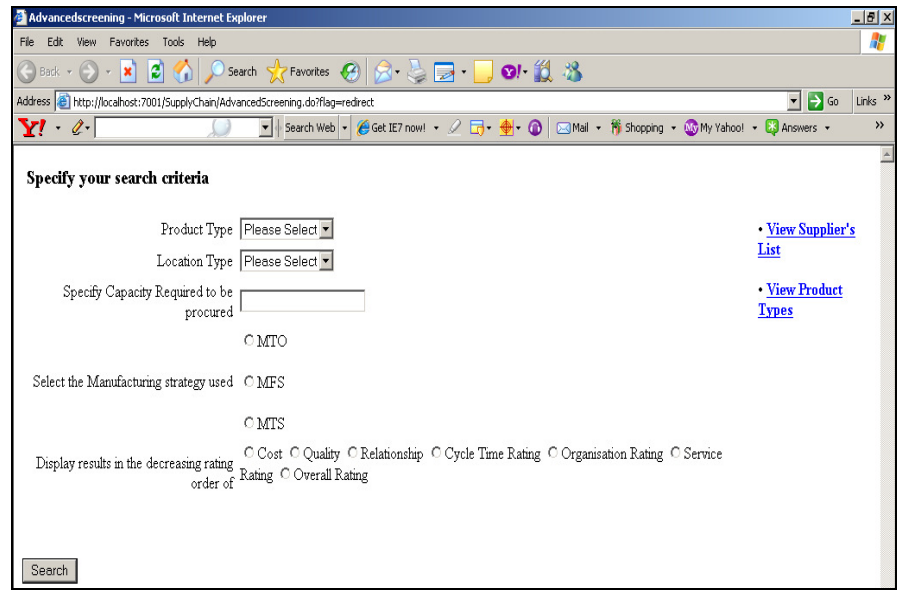

Figure 6 Supplier screening module

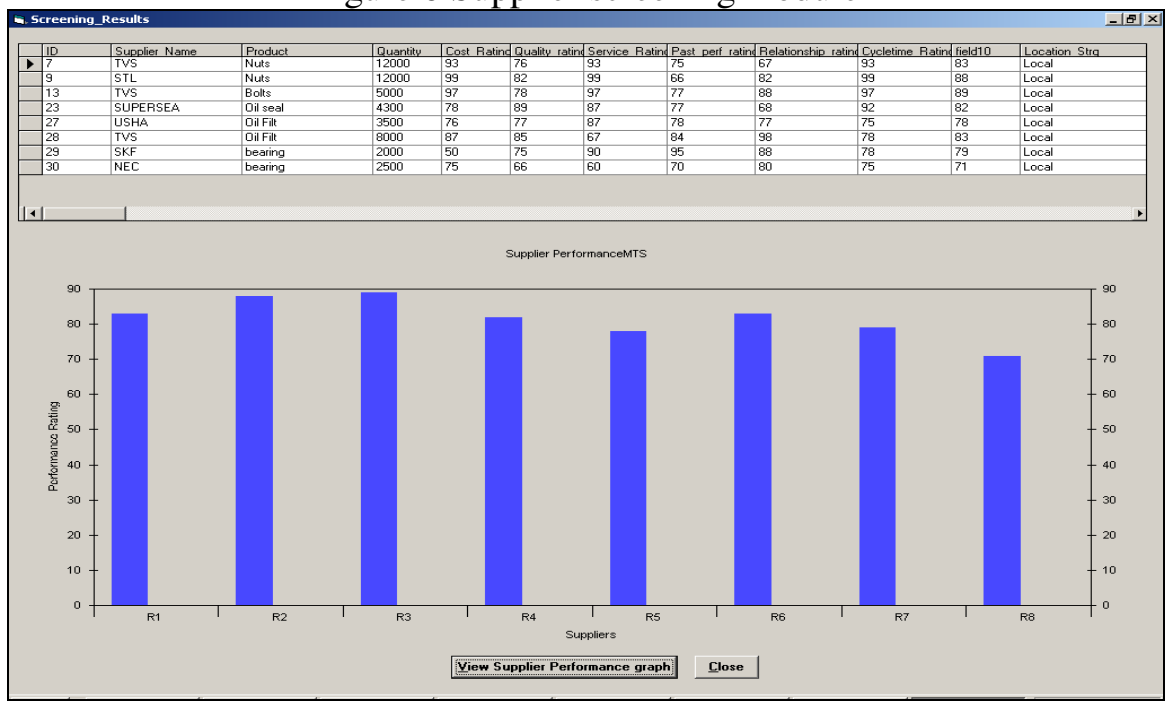

Figure 7 Supplier Screening Component 
International Journal of Database Management Systems ( IJDMS ) Vol.4, No.2, April 2012

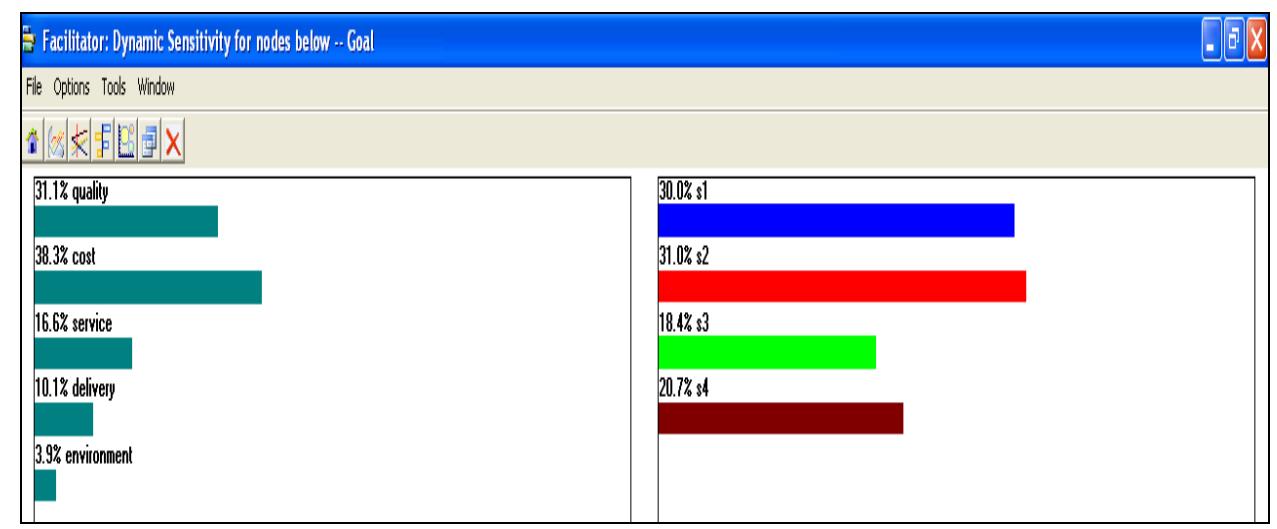

Figure 8 Priorities of the Supplier with respect to Criteria

\section{E-Procurement Implementation}

Finally, after choosing the top " $n$ " suppliers, the e-procurement process shown by the sequence diagram in Figure 9 is implemented using the ASP and SQL Server in an intranet server.

Once the manufacturing industry submits its procurement requirements (E-requirements) to the DSS agent (web agent), the potential suppliers are selected as discussed above and the Request for Proposal (E-RFP) is sent to those potential suppliers as shown in Figure 10. 
International Journal of Database Management Systems ( IJDMS ) Vol.4, No.2, April 2012

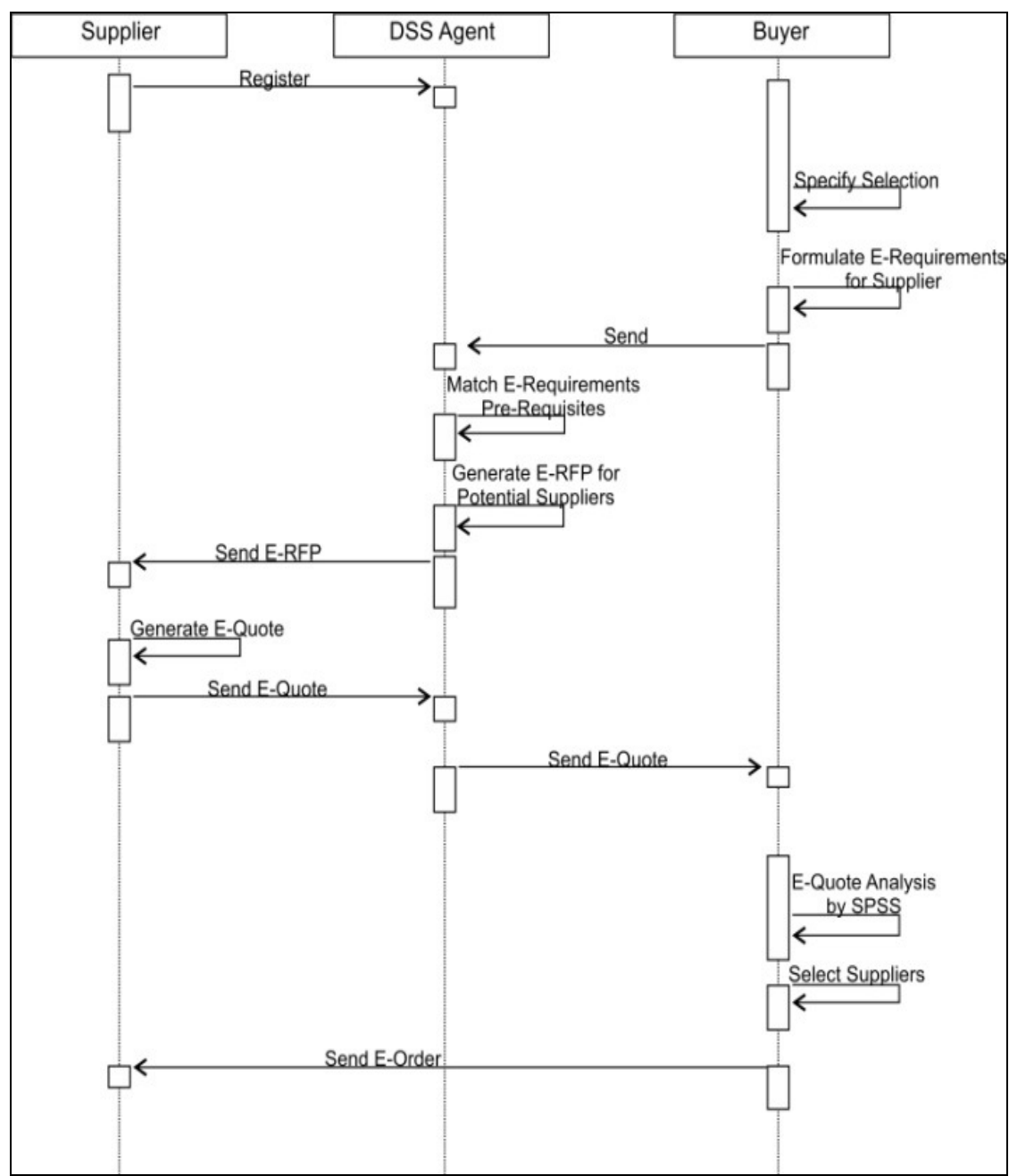

Figure 9 E-procurement sequence diagram

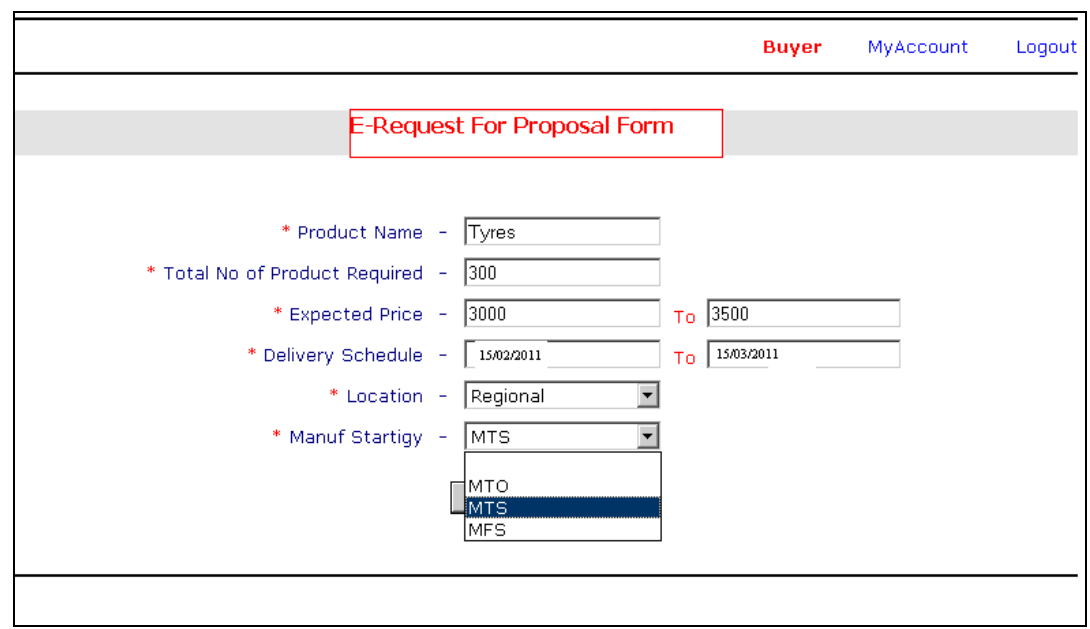

Figure10 E-RFP sent to the supplier 
International Journal of Database Management Systems ( IJDMS ) Vol.4, No.2, April 2012

Upon receipt of the e-RFP, the supplier prepares the quote and submits the e-quote back to the DSS agent as shown in Figure 11.

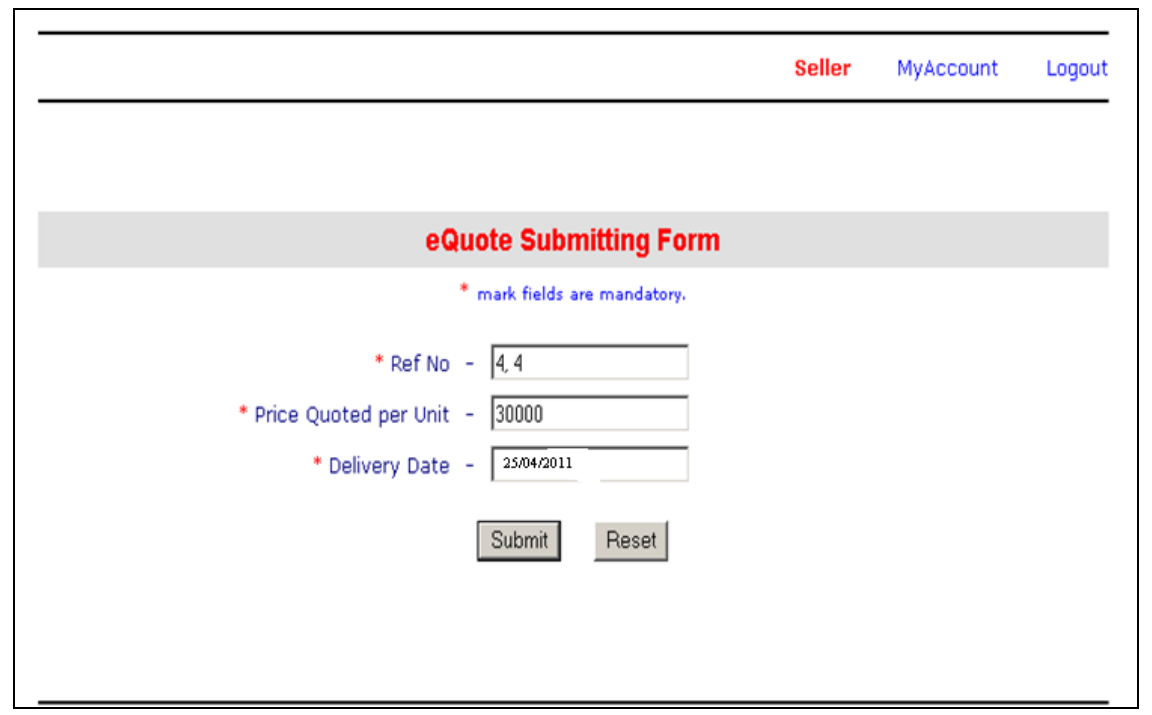

Figure11 E-quote submitted by the suppliers to the Web agent.

The e-Quotes are then forwarded to the buying organization/ procurement managers. Upon receipt of the e-quotes from the top " $n$ " selected suppliers, the procurement team selects the best convincing supplier by summarizing and reviewing the e-quotes by SPSS analysis and then finally sends the e-order to the selected supplier.

\section{Conclusions}

The stand-alone DSS developed is flexible and set up in a modular structure suitable for a multiuser, inter-company usage. The DSS selects key suppliers based on the company's core process requirements (Decision support strategies) and standardized selection criteria. This is done by the standard Operations research tools such as the OLAP and AHP. The supplier screening process is done by means of evaluation and short-listing procedures. The purchasing process is then initiated with this selected list of potential suppliers. The short listed suppliers are ranked by the Analytic Hierarchical Processing technique. The DSS finally recommends this list of short listed suppliers for the e-procurement process.

\section{REFERENCES}

[1] Alev Taskin Gumus, Ali Fuat Guneri, Selcan Keles, Supply chain network design using an integrated neuro-fuzzy and MILP approach: A comparative design study, Expert Systems with Applications, DOI: 10.1016/j.eswa.2009.05.034, 2009.

[2] Ali Fuat Guneri, Atakan Yucel, Gokhan Ayyildiz, An integrated fuzzy-lp approach for a supplier selection problem in supply chain management, Expert Systems with Applications, Vol. 36 Issue 5, DOI: 10.1016/j.eswa.2008.12.021, 2009.

[3] Ali Kokangul and Zeynep Susuz, Integrated analytical hierarchy process and mathematical programming to supplier selection problem with quantity discount, Applied Mathematical Modelling, Vol. 33, Issue 3, pp: 1417-1429, 2009. 
International Journal of Database Management Systems ( IJDMS ) Vol.4, No.2, April 2012

[4] Amir Sanayei, S. Farid Mousavi, M.R. Abdi and Ali Mohaghar, An integrated group decision-making process for supplier selection and order allocation using multi-attribute utility theory and linear programming, Journal of the Franklin Institute, Vol. 345, Issue 7, pp: 731-747, 2008.

[5] Cemalettin Kubat and Baris Yuce, A hybrid intelligent approach for supply chain management system, Journal of Intelligent Manufacturing, DOI: 10.1007/s10845-010-0431-2, 2007.

[6] Davidrajuh, R. (2003) Modeling and implementation of supplier selection procedures for e-commerce initiatives. Industrial Management \& Data Systems, 103(1): p. 28-38.

[7] Jing-Rung Yu, Chao-Chia Tsai, A decision framework for supplier rating and purchase allocation: A case in the semiconductor industry, Computers and Industrial Engineering, Vol. 55 Issue 3, DOI: 10.1016/j.cie.2008.02.004, 2008.

[8] Jose M. Cruz: The impact of corporate social responsibility in supply chain management: Multicriteria decision-making approach. Decision Support Systems 48(1), pp: 224-236, 2009.

[9] Journal of Systems Science and Systems Engineering, Vol. 15, Number 2, pp: 217-231, 2005.

[10] Manoj Kumar, Prem Vrat, R. Shankar, A fuzzy goal programming approach for vendor selection problem in a supply chain, Computers and Industrial Engineering, v.46 n.1, p.69-85, 2006.

[11] Ming-Hung Shu, Hsien-Chung Wu, Quality-based supplier selection and evaluation using fuzzy data, Vol. 57 Issue 3, DOI: 10.1016/j.cie.2009.04.012, 2009.

[12] Keshavamurthy B.N. , Mitesh Sharma and Durga Toshniwal, efficient support coupled frequent pattern mining over progressive databases, International journal of database management systems, Vol.2, No. 2, pp:73 - 82, May 2010.

[13] Paul Humphreys, Ronan McIvor, Felix Chan , Using case-based reasoning to evaluate supplier environmental management performance, Expert Systems with Applications, Vol. 25(2),pp:141-153, 2003.

[14] Qinghua Zhu, Joseph Sarkis and Kee-hung Lai, Initiatives and outcomes of green supply chain management implementation by Chinese manufacturers, Journal of Environmental Management, Vol. 85, Issue 1, pp: 179-189, 2007.

[15] Saman Hassanzadeh Amin, Jafar Razmi, Guoqing Zhang, Supplier selection and order allocation based on fuzzy SWOT analysis and fuzzy linear programming, Expert Systems with Applications, DOI: 10.1016/j.eswa.2010.06.071, 2011.

[16] SPSS tutorial available at: www.spss.com

[17] Süleyman Ersöz, Mustafa Yüzükırmızı, A Kürşad Türker, Burak Birgören, Vendor Selection in Supply Chain Management, Management Science / Operations Research, Vol.: 1, Issue: 2, pp: 61-67, 2009.

[18] Thomas L Saaty, Fundamentals of the Analytic Hierarchy Process. RWS Publications, 4922 Ellsworth Avenue, Pittsburgh, PA 15413, 2000.

[19] Wan Lung, Ng, An efficient and simple model for multiple criteria supplier selection problem, European Journal of Operations Research, 186 (3), pp: 1059 - 1067, 2008. 